\title{
Attention-deficit/hyperactivity disorder - co-morbidity and differential diagnosis
}

M J Shokane, MB ChB, MMed (Psych)

L U Z Rataemane, MPhil, MSOc (Psychol)

S T Rataemane, MB ChB, FFPsych, Dip Child Psych (UK)

Department of Psychiatry, University of the Free State, Bloemfontein

Attention-deficit/hyperactivity disorder (ADHD) is a chronic and disabling condition in children. It is among the most prevalent, chronic health conditions affecting school-aged children.

Children with ADHD may experience significant functional problems, such as school difficulties, academic underachievement, and troublesome interpersonal relationships with family and peers. ${ }^{1,2}$ Parents and teachers may diagnose a child's school problems as being ADHD-related, when in fact the difficulties are unrelated to $A D H D$.

A myriad of disorders mimic ADHD (Table I). Studies of children with ADHD consistently document higher rates of co-morbidity with other psychiatric conditions, including disruptive behavioural disorders, depression and other mood disorders, anxiety disorders, tic disorders, etc. ${ }^{3.7}$ The incidence of co-morbidity ranges from $50 \%$ to $90 \%$. The existence of an additional disorder dramatically affects the prognosis, treatment and health care delivery decisions, ${ }^{3}$ and correctly identifying ADHD is complicated by a high prevalence of co-morbid disorders or the presence of conditions that can be confused with ADHD?

ADHD is a developmental disorder, so symptom manifestation is highly individualistic and core symptoms may shift with age. Hyperactivity and impulsivity tend to become less apparent as the child gets older and inattention and cognitive problems move into the foreground. ${ }^{8 \cdot 10}$ Assessment of the child with behaviour suggestive of ADHD involves an evaluation process that could take considerable time. ${ }^{4,7,11}$

The most commonly prescribed and studied medications in the treatment of ADHD are psychostimulants (methylphenidate and dextroamphetamine). ${ }^{12,13}$ Data on the alternative management (dietary and other psychopharmacological agents) of ADHD and ADHD with co-morbidity have been scarce and controversial. ${ }^{14,15}$

\section{Table I. Summary of conditions that mimic co-morbid ADHD}

\begin{tabular}{|c|c|}
\hline Neurological disorders & $\begin{array}{l}\text { Seizure disorders } \\
\text { Brain trauma } \\
\text { Tic disorders (Tourette's } \\
\text { syndrome) }\end{array}$ \\
\hline Psychiatric disorders & $\begin{array}{l}\text { Anxiety disorders/ post- } \\
\text { traumatic stress disorders: } \\
\text { Obsessive/compulsive disorder, } \\
\text { separation anxiety disorder, } \\
\text { and phobias } \\
\text { Childhood depression } \\
\text { Childhood-onset bipolar } \\
\text { disorder } \\
\text { Substance abuse } \\
\text { Mental retardation } \\
\text { Pervasive developmental } \\
\text { disorders } \\
\text { Disruptive behaviour disorder } \\
\text { (conduct and oppositional } \\
\text { defiant disorders) } \\
\text { Learning disabilities } \\
\text { Childhood psychosis }\end{array}$ \\
\hline Medical disorders & $\begin{array}{l}\text { Chronic diseases such as } \\
\text { congenital heart disease, } \\
\text { asthma, chronic renal failure, } \\
\text { fetal-alcohol syndrome, thyroid } \\
\text { diseases and other endocrine } \\
\text { abnormalities. Sensory } \\
\text { deprivation, i.e. hearing and } \\
\text { visual impairments }\end{array}$ \\
\hline Medications & $\begin{array}{l}\text { Anti-asthmatics (theophylline) } \\
\text { Anti-epileptics (phenobarbital) } \\
\text { Decongestants } \\
\text { Antihistamines } \\
\text { Benzodiazepine withdrawal }\end{array}$ \\
\hline Other & $\begin{array}{l}\text { Parent-child relationship } \\
\text { problems }\end{array}$ \\
\hline
\end{tabular}




\section{Co-morbidity}

\section{ADHD and childhood-onset bipolar disorder}

The clinical presentation of bipolar disorder in children, like the presentation of many other mental illnesses such as schizophrenia, is a challenge for the clinician. The current guidelines for the diagnosis of bipolar disorder in adults are very clear when cultural, occupational, social and educational factors are taken into consideration. ${ }^{16}$ In children, normal developmental issues complicate the picture. In the manic phase, children may demonstrate a large spectrum of clinical symptoms such as irritability, anger, aggression, and oppositional behaviour rather than euphoria. ${ }^{17}$ Short-lived manic outbursts (affective storms), which may be intense in severity, have been witnessed. 5,6,17

In an overview of co-morbidity of ADHD with other psychiatric disorders, Steven R Pliszka et al. ${ }^{5}$ report a variable picture in the prevalence of co-morbidity of ADHD and bipolar disorder. Others have reported a prevalence of $15-75 \%$.,14 The shared symptomatology of distractibility, physical hyperactivity and talkativeness compound the difficulty in determining whether the child has ADHD, bipolar disorder or both. Children with ADHD/bipolar disorder appear to be at greater risk for morbidity and mortality, with higher rates of suicide. ${ }^{14}$

\section{Treatment}

Response to psychostimulants is poor in children with ADHD and bipolar disorder compared with the response of children with ADHD alone. ${ }^{6}$ The combination of lithium carbonate and stimulants in ADHD/manic children is both safe and efficacious. ${ }^{5}$ The combination of stimulants with other mood stabilisers needs to be researched.

\section{Anxiety disorders and ADHD}

The prevalence of anxiety disorders in children with ADHD ranges from $20 \%$ to $30 \%$. $^{1,3,5,6,14}$ Children with anxiety disorders are preoccupied with worry or fear. They have difficulty sleeping at night, and therefore become restless, fidgety and agitated, and may have ritualistic behaviours, throw temper tantrums and become attention seeking during the day. Many of these symptoms may be misinterpreted as being those of ADHD. Children with anxiety disorders are not truly hyperactive. ${ }^{3,7}$ The symptom presentation of anxiety disorders may easily overlap with that of ADHD.' Particular attention should be given to the presentation of generalised anxiety disorder, simple phobia, agoraphobia, obsessive-compulsive disorder and post-traumatic stress disorder. ${ }^{3,7}$
In obsessive-compulsive disorder, for instance, children may recognise the obsessional thoughts as being a product of their own minds, and therefore attempt to ignore or suppress them. This may lead to inattention when they are expected to concentrate. Carrying out the compulsion, which may be silent, may cause the child to be absentminded in the classroom and therefore to perform poorly.

\section{Treatment}

Children with anxiety disorders/ADHD show limited response to stimulants. ${ }^{5}$ They frequently develop side-effects from stimulants. ${ }^{5}$ Antidepressants may play an important role, given their ability to treat anxiety disorders and ADHD as separate disorders. The efficacy of anxiolytic agents such as buspirone in the management of ADHD/anxiety disorders has not been reported in the literature. Benzodiazepines are not recommended, as they may aggravate restlessness and aggression. ${ }^{3}$

\section{ADHD and depression}

Depressive disorders may be another source of confusion in trying to establish a diagnosis of ADHD.? The mood in childhood depression may be irritable rather than depressed, and the onset tends to be later than age 7 years. ${ }^{1,6}$ Other features may include school dysfunction, negativism, somatic symptoms, social withdrawal, significant weight loss or gain, sleep problems with insomnia or hypersomnia, aggression and antisocial behaviour. Their fatigue from insomnia may be misinterpreted as inattention or lack of motivation. ${ }^{1,3,5,17}$ The presence of dysthymia, a lowgrade chronic form of depression, may be the most accurate predictor of future episodes of depression as well as long-term psychosocial difficulties. ${ }^{3}$

ADHD and mood disorders in general have been found to cooccur in $15-75 \%$ of cases. ${ }^{5,14}$ The prevalent rate for depressive disorders in children with ADHD ranges from $9 \%$ to $38 \%,{ }^{5}$ and the depressive symptoms generally have an onset after the ADHD symptoms. ${ }^{17,18}$ It is further suggested that ADHD does not increase the risk of suicide attempts/suicide completion, but that co-morbid conduct disorder or substance abuse do. ${ }^{17}$

\section{Treatment}

Antidepressants may have a particular role to play in the treatment of patients with ADHD and co-morbid depression, given their ability to treat both depression and ADHD as separate entities. ${ }^{4}$ 


\section{ADHD and disruptive behaviours (conduct disor- der/oppositional defiant disorder)}

In both oppositional-defiant and conduct disorders, there is a pervasive pattern of aggression, violation of rules and regulations, temper outbursts, and annoying behaviours that exceed expectation for the child's age. ${ }^{16,19}$ These groups of disorders, like ADHD, are more common in boys than girls. ${ }^{8,19}$ ADHD and the group of disruptive behaviour disorders co-occur in 20 - 50\% of cases. $3,5,6,14,15,20$ Conduct disorder is a more severe disorder with habitual rule breaking, a pattern of aggression, destruction, lying theft, truancy and cruelty to others and animals. ${ }^{2,3,6,19}$ In children with conduct disorder/ADHD contact with the law may be at a very early age, with resultant poor outcome in the long term. Also increased are the rates of drug and alcohol abuse or dependency disorders, with $30-40 \%$ of these children progressing into adult antisocial personality disorders., 3,6

\section{Treatment}

In both the short and long term the response rate to psychostimulant medications is no different for ADHD alone and ADHD with disruptive behaviours. Other forms of psychological treatment in combination with pharmacotherapy may be tried. ${ }^{21}$ Children with co-morbid disruptive behaviour are more likely to default therapy, including stimulant medications, than those with ADHD alone. $^{22}$

Lithium carbonate (a mood stabiliser) has been found to be effective in the control of aggression in the child with co-morbid conduct disorder. ${ }^{5}$

\section{ADHD and learning disabilities}

The overlap with learning disorders ranges from $6 \%$ to $92 \%$ in children with ADHD. ${ }^{3,5}$ Learning difficulties can occur in reading, in specific subjects like mathematics, written or language expression, and can be either receptive or expressive in nature. Early signs of learning disability may include delayed speech, difficulty following commands, fine motor delays, poor memory skills, clumsiness, inattention, difficulty differentiating left from right and a dislike for learning to read or write.'

These symptoms may go unrecognised or are thought to be caused by ADHD alone. ${ }^{19}$ Children with ADHD may perform poorly in school with more grade repetitions, poor grades in academic subjects and frequent placement in special classes. The academic and learning problems may persist into adolescence. They are often associated with chronic underachievement and school failure. ${ }^{14}$
Reading disabilities affect 2 - $8 \%$ of school-aged children, whereas the rate of writing and mathematics disabilities is unknown. ${ }^{18}$ These disorders, like ADHD, are more common in boys than girls. 8,18,19 The frustration associated with impairment in academic skills can lead to a variety of complications, such as truancy, school refusal, conduct disorders, mood disorders and substance abuse. ${ }^{18}$

\section{Treatment}

In terms of treatment, patients with reading difficulties do not show improved reading skills when treated with psychostimulants, but children with co-morbid ADHD do. ${ }^{18}$

\section{ADHD and substance abuse}

ADHD with or without co-morbidity is a risk factor for the occurrence of substance abuse among adults. ${ }^{17}$ Academic difficulties experienced by children with ADHD can predispose them to substance abuse. The presence of co-morbid conduct disorder significantly increases the risk of substance abuse. The clinician should first attempt to stabilise and treat the substance use disorder. ${ }^{17}$ In a study ${ }^{23}$ of 120 consecutively referred adults with a diagnosis of childhood ADHD, the researchers concluded that ADHD significantly increases the risks of substance use disorder irrespective of any psychiatric co-morbidity.

\section{Treatment}

Psychostimulant medications are considered to be safe and efficacious for the treatment of ADHD among substance abusing individuals, without increasing the rate of substance abuse in the long term. ${ }^{17,24}$ Bupropion (an antidepressant with both noradrenergic and dopaminergic neurotransmission properties) and tricyclic antidepressants are considered effective in children/adolescents with co-morbid ADHD and substance use disorders. ${ }^{17,25}$

\section{Tics and ADHD}

The co-occurrence of ADHD and tic disorder is the focus of major scientific controversy. ${ }^{27}$ Approximately $60 \%$ of children with Tourette's syndrome have been shown to have co-morbid ADHD. ${ }^{1,14,19}$

Other than motor and vocal tics, children with Tourette's syndrome may also have obsessions and compulsions, impulsivity, hyperactivity and distractibility. ${ }^{18,19}$ Some of these symptoms are found in ADHD. Boys are more affected than girls. These children also have academic difficulties. 1,18,19 


\section{Treatment}

The treatment of children with ADHD and tic disorder is controversial. The use of stimulant medication has been associated with worsening of tic disorders in some patients. 3,19,26 For many years haloperidol has been used as the first line in the treatment of Tourette's disorder. ${ }^{18,19}$ Methylphenidate has been noted to be effective for ADHD behaviours, aggression, and social skill deficits in children with Tourette's syndrome or chronic tic. ${ }^{3}$

\section{Other disorders}

\section{Developmental disorder}

Children with developmental disorders such as mental retardation and pervasive developmental disorders (autism, Asperger's syndrome, Rett's disorder and childhood disintegrative disorder) often have additional psychiatric and behavioural problems. These include hyperactivity, aggression, inattention, self injury, stereotyping, impaired social interaction and poor peer relationships. ${ }^{13,18,19}$ The presenting symptoms in these children are generally noticeable much earlier than ADHD symptoms. ${ }^{16,18,19}$

\section{Treatment}

The treatment of aggression, agitation and self-injurious behaviour has involved a wide spectrum of agents. Beta-blockers and alpha-adrenergic modulators (clonidine and guanfacine), and antipsychotics such as haloperidol have been reported to be useful in symptomatic control. Antidepressant medications and mood stabilisers have also been noted to be effective in the control of affective symptoms, aggression and agitation in this group of children. ${ }^{3,18,19}$ Anxiolytic agents such as benzodiazepines should be used with caution, as they tend to produce disinhibition which often results in restlessness and more disturbed behaviour. ${ }^{3}$ Anti-epileptic agents such as phenytoin and phenobarbitone may produce disinhibition and restlessness in the mentally retarded as a side-effect.

\section{Medical disorders}

Sensory impairment can markedly affect the child's development, attention span, social interactions and school performance. Children with undetected hearing loss may present with behaviour problems that can mimic ADHD. ${ }^{1,4}$

\section{Chronic illnesses and other medications}

Chronic medical problems occur in up to $20 \%$ of school-aged children in the USA.' Conditions such as migraine headaches, petit mal seizures, thyroid disorders (hypo/hyperthyroidism), diabetic mellitus' and medications such as phenobarbitone and other anticonvulsants, decongestants, oral steroids, antihistamines and anti-asthmatics can impact on the child's behaviour ${ }^{1,4}$ and classroom performance.

\section{Sleep disorders}

About $20-30 \%$ of children have sleep problems that are considered significant by their families. An increased rate of behavioural and emotional symptoms has been observed in about $34 \%$ of children with sleep problems.' Children with ADHD have been noted to require less sleep than their peers (they go to bed late, and rise earlier than their peers). ${ }^{4}$ Sleep problems can be the cause or result of emotional and behavioural difficulties in children. ${ }^{1,4}$

\section{Psychopharmacology of ADHD - children, adolescents and adults}

While ADHD was originally conceptualised as a disorder of childhood, its status as a disorder in adults is uncertain. Various studies have found that $10-60 \%$ of childhood ADHD progresses into adult $A D H D .{ }^{24,27.29}$ The diagnosis of adult $A D H D$ requires the presence of the disorder from childhood. 6,2830

\section{Drug therapy}

The pathogenesis of ADHD appears to be mediated through dopaminergic and adrenergic systems. ${ }^{3033}$ Serotonin does not appear to play a crucial role in ADHD.

\section{Stimulants}

Psychostimulant medications are the mainstay in the treatment of both childhood and adult ADHD. The safety and efficacy of these agents have been well established. ${ }^{34}$ The use of psychostimulants with co-morbid substance use disorder has not been associated with increased risk of substance abuse. 17,27,30,35,36 For adults with $A D H D$, the duration of action of psychostimulants is extremely short, therefore requiring frequent dosing. This may prove difficult for the patient with ADHD. ${ }^{30}$ 'Drug holiday' may prove to be difficult in adult patients required to keep their finger on the daily running of families and work situations.

The dosage range of methylphenidate in adults is 40 - $90 \mathrm{mg} /$ day, while children with ADHD should not receive more than $60 \mathrm{mg} /$ day. 12,30,35 The average dosage for children with $\mathrm{ADHD}$ is $0.3-0.8 \mathrm{mg} / \mathrm{kg}$ body weight, whereas in adults it is $1.0 \mathrm{mg} / \mathrm{kg}$ of body weight. $28,30,33,35$ In both adults and chil- 
dren the dosage frequency remains 2 - 3 hours.

Dextroamphetamine is given at a dosage range of 20 - 45 $\mathrm{mg} /$ day for both adult and childhood ADHD. Sustained release versions of both methylphenidate and dextroamphetamine are currently available in the USA. These may allow single dosing per day. The duration of action of these agents is up to 8 hours. This may improve compliance. ${ }^{7,8}$ The absence of co-morbidity such as oppositional defiant disorder influences long-term compliance with stimulant medication. ${ }^{22}$ Pemoline is, however, associated with fatal hepatotoxicity and requires liver function monitoring. ${ }^{30,35}$ Common adverse reactions to stimulant medications include headaches, rebound irritability, anorexia, weight loss, dyspepsia, insomnia, nightmares, dysphoria, slowed growth, worsening of co-morbid tic disorder, leucopenia and psychosis. ${ }^{3,19,26,35}$ Stimulant-related psychosis has not been witnessed in adults.

\section{Other agents}

Approximately $70 \%$ of patients on stimulant medications will experience therapeutic effect. Those who fail a therapeutic trial of one stimulant may respond to another. ${ }^{28,35}$ However, other psychotherapeutic agents have been used in patients who for a variety of reasons do not respond to or cannot tolerate psychostimulants. These include alpha-2 agonists, antidepressants and antipsychotics.

Antidepressants. Tricyclic antidepressants have been widely studied in the treatment of ADHD in both adults and children. ${ }^{30,35,37,38}$ The most widely studied tricyclic antidepressants are nortriptyline, amitriptyline, desipramine and imipramine..$^{4,37}$ Other groups of antidepressants have been studied in ADHD patients, including the newer groups. Monoamine oxidase inhibitors have been reported to be effective, but dietary restrictions limit their use in clinical settings. ${ }^{30,35}$

This overview reports that tricyclic antidepressants are not useful in the management of ADHD in both adults and children. The patients in these studies were seen to develop tolerance to tricyclic antidepressants despite increase in dosage. ${ }^{30}$ In adults with co-morbid anxiety or depressive symptoms, tricyclic antidepressants have been reported to be efficacious. ${ }^{28,30,37}$

Selective serotonin re-uptake inhibitors have had beneficial effects on ADHD patients with co-morbid major depressive disorder or dysthymia. ${ }^{30}$

Bupropion is reported to be efficacious in patients with co-morbid ADHD and depression. 17,30,35,39 Data on efficacy of newer antidepressants are not readily available.

With regard to alpha-2 agonists, clonidine has been used alone or in combination with psychostimulants in ADHD. 35,37,39 Careful cardiovascular monitoring including electrocardiographic (ECG) monitoring is highly recommended in patients on clonidine/stimulant due to reports of unexplained death from this combination. ${ }^{35,39}$ Clonidine alone has been reported to induce euphoria. ${ }^{35}$

Antipsychotics. Antipsychotic medications in ADHD have included both low-potency agents such as thioridazine and chlorpromazine and high-potency agents like haloperidol. These are generally considered the last measure in the treatment of ADHD. ${ }^{35}$

\section{Controversial treatments of ADHD}

A variety of alternative treatments have been tried, not only in the management of $A D H D$, but also in a variety of ailments in medicine. These methods tend to lack scientific validation, ${ }^{15}$ and are often controversial in application. Despite scientific uncertainty about their mode of action and the often complex explanations of their efficacy these methods have found home in both the scientific and lay communities.

Some of these treatments have involved dietary management, herbs and antioxidants, vision therapy, oculovestibular treatments, homeopathy, auditory stimulations, etc. ${ }^{15}$ It is not the intention of this review to engage in a detailed discussion of the controversial management of ADHD, and ADHD with co-morbidity.

\section{Conclusion}

$\mathrm{ADHD}$ is a chronic disorder of childhood that progresses into adult ADHD in a significant number of children. The clinical presentation of ADHD easily overlaps with other disorders of childhood. ADHD can also co-occur with other psychiatric conditions of childhood in a significant number of children. This has led to diagnostic confusion among clinicians and other health personnel dealing with children's mental health. The differing diagnostic criteria as laid out in the International Classification of Diseases 10 (ICD-10) and the Diagnostic and Statistical Manual IV IDSM$M$ compound the picture. Therefore, for the clinician tasked with children's mental health, a thorough psychiatric history followed by both medical and neurological assessments should precede a diagnosis of ADHD in a child.

The treatment of choice in both adults and children with ADHD is 
psychostimulants. Several controversies around the use of psychostimulants in ADHD have found their way into both the scientific and lay communities. These have tended to criticise the diagnosis of ADHD as being unnecessary. The use of psychostimulant medications (methylphenidate and dextroamphetamine) has also come under severe criticism. Despite all these unfounded criticisms, psychostimulants remain the treatment of choice in ADHD.

\section{References}

1. Buttross S. ADHD and its deceivers. Curr Probl Pediatr 2000; 30(2): 37-50

2. American Academy of Pediatrics. Committee on Quality Improvement, Subcommittee on ADHD. Clinical practice guidelines: Diagnosis and the evaluation of the child wi h ADHD. Pediatrics 2000; 105: $1158-1170$.

3. Spencer T, Bierderman J, Wilkens T. ADHD. and comorbidity. Pediatr Clin North Am 1999; 4: $915-927$

4. Pasquale A. A rational approach to the medical assessment of he child with ADHD. Pediatr Clin North Am 1999; 4: 845-855.

5. Pliszka SR. Comorbidity of ADHD with psychiatric disorder: an overview. J Clin Psychiatry 1998; 59: suppl 7, 50-58.

6. Enerst SL, Luk ESL, Alasdair L, Vance A. ADHD, Current problems and controversies. Aust N ZJ Psychiatry 2000; 34: $719-730$

7. Dunne JE. ADHD and associated childhood disorders. Prim Care 1999; 26: 349 372.

8. Nurcombe B, Wolraich ML, Tramontana M, Stone W. Disorders usually presenting in infancy or early childhood. Current Diagnosis and Treatment in Psychiatry 2000: 533-586.

9. Shaffer D. ADHD in adults. Am J Psychiatry 1994; 15 1: 633-638.

10. Hornig M. Addressing comorbidity in adults with ADHD. J Clin Psychiatry 1998; 59: suppl 7, 69-75.

11. Morgan AM. Diagnosis of ADHD in the office. Pediatr Clin North Am 1999; 46: 871-884.

12. The Texas Children's Medication Algorithm Project. Report of the Texas Conference Panel on medication treatment of childhood ADHD. Part II: Tactics. J Am Acad Child Adolesc Psychiatry 2000; 39: 920-927.

13. Goldman LS, Genef M, Bezman R, Slanetz P. Diagnosis and treatment of ADHD in children and adolescents. JAMA 1998; 279: $1100-1107$.

14. Bierderman J, Newcorn J, Sprich S. Am J Psychiatry 1991; 148: 564-577.

15. Baumgaertel A. Alternative and controversial treatments for ADHD. Pediatr Clin North Am 1999; 46: 977-991.

16. American Psychiatric Association. Diagnostic and Statistical Manual of Mental Disorders. 4th ed. Washington, DC: APA, 1994

17. $154 \mathrm{~h}$ Annual Meeting of the American Psychiatric Association, 8 May 2001 ADHD and comorbidity.
18. Andreasen NC, Black DW. Introductory Textbook of Psychiatry. 2nd ed. 545-582.

19. Kaplan and Sadock's Synopsis of Psychiatry: Behavioural Sciences/Clinical Psychiatry. 8th ed. Chapters 36-45.

20. Greenhill LL. Diagnosing ADHD in children. Clin J Psychiatry 1998; 59: suppl 7 , $31-41$.

21. Rey JM. Oppositional defiant disorders. Am J Psychiatry 1993; 150: 1769-1777.

22. Thiruchelvam D, Charach A, Schachar RJ. Moderators and mediators of long-term adherence to stimulant treatment in children with ADHD. J Am Acad Child Adolesc Psychiatry 2001 ; 40: 922-928

23. Bierderman J, Wilens T, Mick E, Milberger S, Spencer TJ, Faroane SV. Psychoactive substance use disorders in adults with ADHD: Effects of ADHD and psychiatric comorbidity. Am J Psychiatry 1995; 152: 1652-1658.

24. Levin FR, Evans SM, McDowell DM, Kleber HD. Methylphenidate treatment for cocaine abusers wi h adult ADHD: A pilot study. J Clin Psychiatry 1998; 59: 300305 .

25. Bierderman J, Wilens $T$, Mick E, et al. Is ADHD a risk factor for psychoactive substance use disorders? Findings from a four-year prospective follow up study. J Am Acad Adolesc Psychiatry 1997; 36 11): 21-29.

26. Nolan EE, Gadow KD, Sprafkin J. Stimulant medication wi hdrawal during long-term therapy in children wi h comorbid ADHD and chronic multiple tic disorder. Pediatric 1999: 103: 730-737.

27. Bierderman J, Faraone S, Spencer T, et al. Patterns of psychiatric comorbidity, cognition and psychosocial functioning in adults with ADHD. Am J Psychiatry 1993; 150: $1792-1797$

28. Spencer T, Bierderman J, Wilens TE, Faraone SV. Adults wi h ADHD: A controversial diagnosis. J Clin Psychiatry 1998; 59: suppl 7, 59-68.

29. Bierderman J. ADHD: A life-span perspective. J Clin Psychiatry 1998; 59: suppl 7, 416.

30. Wender PH. Pharmaco herapy of ADHD in adults. J Clin Psychiatry 1998; 59: suppl 7, 76-79.

31. Zametkin AJ, Liotta W. The neurobiology of ADHD. J Clin Psychiatry 1998; 59: suppl 7, 17-23

32. Levy F, Barr C, Sunohara G. Directions of aetiologic research on ADHD. Aust NZJ Psychiatry 1998; 32: 97-103.

33. Challman TD, Lipsky JJ. Me hylphenidate: Its pharmacology and uses. Mayo Clin Proc 2000; 75: 711 1-721.

34. Safer DJ, Zito JM, Fine EM. Increased me hylphenidate usage for attention deficit disorder in the 1990s. Pediatrics 1996; 98: 1084-1088.

35. Findling RL, Dogin JW. Psycopharmacology of ADHD: Children and adolescents. J Clin Psychiatry 1998; 59: suppl 7, 42-49.

36. Wolraich ML, Lindgren S, Stromquist A, Milich R, Davis C, Watson D. Stimulan medication use by Primary Care Physicans in the treatment of ADHD. Pediatrics 1990: 86 (1): 95-101

37. Committee on Children wi h Disabilities and Committee on Drugs. Medications for children with attentional disorders. Pediatrics 1996; 98: 301-304.

38. Angold A, Costello EJ. Depressive comorbidity in children and adolescents: Empirical, heoretical and me hodological issues. Am J Psychiatry 1993; 150: 1779-1791.

39. Silver LB. Alternative (nonstimulant) medications in the treatment ADHD in children. Pediatr Clinic North Am 1999; 46: 965-974. 